\title{
Fulminant skin necrosis and massive deep venous thrombosis as a part of a clinical presentation of polyarteritis nodosa -case report
}

\author{
Adisa Čengićc ${ }^{*}$, Senka Mesihović Dinarević ${ }^{2}$ Aida Omerčahić Dizdarević ${ }^{1}$, Velma Selmanović ${ }^{1}$ Emir Kurtalić ${ }^{3}$ \\ From 21st European Pediatric Rheumatology (PReS) Congress \\ Belgrade, Serbia. 17-21 September 2014
}

\begin{abstract}
Introduction
Polyarteritis Nodosa (PAN) is a systemic, necrotizing vasculitis that affects medium-sized and small muscular arteries resulting in microaneurysm formation. In the presteroid era, mortality was high and the diagnosis was exclusively made postmortem.
\end{abstract}

\section{Objectives}

Our goal is to present very challenging, biopsy proven, case od PAN which resulted in massive necrotic skin lesions and deep venous thrombosis.

\section{Methods}

We report the case of 8 year old boy who was referred to our hospital with 11 days history of high fever $\left(39.5^{\circ} \mathrm{C}\right)$, fatigue, anorexia and weight loss. Two days prior to admission he began to complain of pain in the calves muscles, developed petechial skin rash and hematomas, gross haematuria and gastrointestinal (GI) bleeding. At admission was febrile, in very poor condition, hyperventilating, with calf muscle tenderness (mostly gastrocnemius and soleus muscles), scrotal pain, unable to walk. Skin findings: livedo reticularis, multiple hematomas, petechie, subcutaneous nodules. On the second day he developed cutaneous necrosis, five days after admission bilateral legs edema was observed. Doppler ultrasonography showed massive deep end superficial venous thrombosis. He was tested negative for hepatitis $\mathrm{C}$ antibodies, perinuclear antineutrophilic cytoplasmic antibody (pANCA) and cytoplasmic antineutrophilic cytoplasmic antibody (cANCA). A deep skin biopsy was performed and showed fibrinoid necrosis of small muscular arteries with leukocytic infiltrate; finding

${ }^{1}$ Allergology, Rheumatology and Clinical Immunology, University Clinical

Center Sarajevo, Bosnia and Herzegovina

Full list of author information is available at the end of the article compatible with polyarteritis nodosa. Kidney biopsy was contraindicated because the boy had agenesis of the right kidney.

\section{Results}

Patient responded well to the aggressive immunosuppressive therapy in terms of halting progression of skin necrosis and gradually resolving haematuria, GI bleeding, muscle and scrotal pain. Thrombosis were treated with intravenous and subcutaneous heparin with good respons. Cutaneous necrosis required skin transplantation. At present time, 18 months after disease onset, PAN is in remission and there are total recanalisation of deep and superficial lower extremities veins.

\section{Conclusion}

PAN is life-threatening disease that often presents with multiorgan involment, but is rarely associated with deep venous thrombosis. Pain and swelling of the lower extremities is not always a symptom of the disease itself, but may indicate another very serious condition such as deep venous thrombosis. Disease requires promt diagnosis and aggressive immunosuppressive treatment to reduce morbidity and mortality.

\section{Disclosure of interest}

None declared.

\section{Authors' details}

${ }^{1}$ Allergology, Rheumatology and Clinical Immunology, University Clinical Center Sarajevo, Bosnia and Herzegovina. ${ }^{2}$ Pediatric Cardiology, Childrens Hospital, University Clinical Center Sarajevo, Bosnia and Herzegovina. ${ }^{3}$ Department for Adult Angiology, Hospital for Vascular Diseases, Sarajevo, Bosnia and Herzegovina. 
- Convenient online submission

- Thorough peer review

- No space constraints or color figure charges

- Immediate publication on acceptance

- Inclusion in PubMed, CAS, Scopus and Google Scholar

- Research which is freely available for redistribution 